\title{
The development and validation of the King's Sarcoidosis Questionnaire for the assessment of health status
}

\author{
Amit Suresh Patel, ${ }^{1}$ Richard J Siegert, ${ }^{2}$ Daniel Creamer, $^{3}$ Genevieve Larkin, ${ }^{4}$ Toby \\ M Maher, ${ }^{5}$ Elisabetta A Renzoni, ${ }^{5}$ Athol U Wells, ${ }^{5}$ Irene J Higginson, ${ }^{6}$ Surinder \\ S Birring ${ }^{1}$
}

- Additional data are published online only. To view these files please visit the journal online (http://dx.doi. org/10.1136/thoraxjnl-2012 201962)

${ }^{1}$ Division of Asthma, Allergy and Lung Biology, King's College London, London, UK ${ }^{2}$ School of Public Health and Psychosocial Studies and School of Rehabilitation and Occupational Studies, AUT University, Auckland, New Zealand

${ }^{3}$ Department of Dermatology, King's College Hospital, London, UK

${ }^{4}$ Department of

Ophthalmology, King's College Hospital, London, UK

${ }^{5}$ Department of Respiratory Medicine, Royal Brompton Hospital, London, UK ${ }^{6}$ Department of Palliative Care, Policy and Rehabilitation, Cicely Saunders Institute, King's College London, London, UK

\section{Correspondence to} Dr Surinder S Birring, Division of Asthma, Allergy and Lung Biology, King's College London, Denmark Hill, London SE5 9RS, UK; surinder.birring@ nhs.net

Received 25 March 2012 Accepted 5 September 2012 Published Online First 12 October 2012
To cite: Patel AS, Siegert RJ, Creamer D, et al. Thorax 2013, 68, 57-65

\begin{abstract}
Rationale Health status is impaired in patients with sarcoidosis. There is a paucity of tools that assess health status in sarcoidosis. The objective of this study was to develop and validate the King's Sarcoidosis Questionnaire (KSQ), a new modular health status measure.
\end{abstract}

Methods Patients with sarcoidosis were recruited from outpatient clinics. The development of the questionnaire consisted of three phases: item generation; item reduction, Rasch analysis to create unidimensional scales and validation; repeatability testing.

Results 207 patients with sarcoidosis (organ involvement: 184 lung, 54 skin, 45 eye disease) completed a 65 -item preliminary questionnaire. 36 items were removed due to redundancy or poor fit to the Rasch model. The final version of the KSQ consisted of five modules (General health status, Lung, Skin, Eye, Medications). Internal consistency assessed with Cronbach's $\alpha$ coefficient was $0.70-0.93$ for KSQ modules. Concurrent validity of the Lung module was high compared with St George's Respiratory

Questionnaire ( $r=-0.83)$ and moderate when compared to forced vital capacity $(r=0.49)$. Concurrent validity with skin-specific and eye-specific measures ranged from $r=$ -0.4 to 0.8 . The KSQ was repeatable over 2 weeks $(n=39)$, intraclass correlation coefficients for modules were 0.90-0.96.

Conclusions The KSQ is a brief, valid, self-completed health status measure for sarcoidosis. It can be used in the clinic to assess sarcoidosis from the patients' perspective.

\section{INTRODUCTION}

Sarcoidosis is a multisystem disorder characterised by granulomatous inflammation. ${ }^{1}$ The lungs are the most frequently affected organ with skin, eye and lymphatics the most common extrapulmonary sites. ${ }^{2}$ Chronic sarcoidosis often causes significant organ dysfunction and morbidity. Dyspnoea, cough, pain, fatigue, depression, skin disfigurement and visual impairment are frequent symptoms. ${ }^{1}$ 3-5 Corticosteroids are often prescribed to treat organ dysfunction and troublesome symptoms. Lung function and other measures such as the Sarcoidosis Severity Tool can be used to assess the severity of pulmonary disease but they do not

\section{Key messages}

What is the key question?

- To develop a brief tool to assess the health status of patients with sarcoidosis.

What is the bottom line?

- The King's Sarcoidosis Questionnaire is a validated tool suitable for clinical and research use.

\section{Why read on?}

- The King's Sarcoidosis questionnaire may become an important outcome parameter in the evaluation of therapies for sarcoidosis.

assess the impact of the disease from the patient's perspective. ${ }^{6}$ Recent studies have reported a significant impairment in health status of patients with sarcoidosis. $^{4-9}$ There is a paucity of sarcoidosisspecific patient-reported outcomes that assess health status. We aimed to develop and validate the King's Sarcoidosis Questionnaire (KSQ), a modular, multi-organ health status measure for patients with sarcoidosis for use in clinic and the evaluation of therapies.

\section{METHODS}

\section{Phase 1: item generation}

A preliminary questionnaire was developed following a review of health status and sarcoidosis literature; a review of available health status questionnaires; face-to-face semi-structured and cognitive interviews with 23 consecutive patients with sarcoidosis who were not involved with validation of the preliminary KSQ; and a multidisciplinary team meeting consisting of respiratory, rheumatology, dermatology, ophthalmology, neurology and palliative care physicians, nurses, a pharmacist, social worker and physiotherapist. The in-depth patient interviews aimed to identify health status issues and explore the impact of their condition. The interviews began with open-ended questions, for example: 'What is it like to live with your sarcoidosis?' and 'How does sarcoidosis affect you?' Patients were also asked questions about 
issues anticipated to be relevant to them and to comment on a preliminary KSQ questionnaire. The interviews were repeated until they no longer yielded new themes. A modular questionnaire was developed since sarcoidosis is a condition with variable organ involvement. The questionnaire was worded to assess health status during the previous 2 weeks and patients responded on a seven-point Likert scale. The Likert response scale was derived from a literature review, multi-disciplinary team meeting and patient interviews. The wording of scales was tailored to individual items.

\section{Subjects}

Consecutive patients with sarcoidosis were recruited from secondary care (King's College Hospital) and tertiary care (Royal Brompton Hospital) specialist clinics from May 2010 to January 2011. Clinical characteristics, comorbid medical conditions and medications were recorded using a structured questionnaire. The diagnosis of sarcoidosis and organ involvement was established when there were typical histological and clinical features using the 'A Case-Control Epidemiologic Study of Sarcoidosis' definitions. ${ }^{10}$ Patients self-completed health status questionnaires independently when attending clinic. The questionnaires were administered by a member of the research team not involved in the clinical care of the patient. Patients were excluded from the study if they could not read the questionnaire or completed less than $85 \%$ of the questionnaire. The diagnosis of sarcoidosis was established within a multi-disciplinary team of clinicians, radiologists and pathologists. Patients were asked 'did you find the questionnaire difficult to complete' and the time taken for completion of the questionnaire was recorded.

\section{Phase 2: item reduction and validation of the KSQ} Item reduction

Items demonstrating a minimum response (floor effect), maximum response (ceiling effect) of $\geq 60 \%$ and the weaker item of those with high inter-item correlations $(r>0.8)$ were removed to minimise redundancy. ${ }^{11}$

\section{Rasch analysis}

The Rasch model provides a template for testing the validity of a questionnaire as a unidimensional measure of the construct it is designed to assess. ${ }^{12}$ It assumes that the response to an item is determined by two factors; the health status of the person and health status impairment represented by the item. A questionnaire that meets the requirements of a Rasch model has interval scaling properties. Patients are more likely to respond to items assessing less severe health status and less likely to items assessing more severe health status. Rasch analysis is an iterative process whereby the poorest fitting item is removed and the remaining items re-tested until a reliable, unidimensional scale is identified.

Rasch analysis was applied to the KSQ modules and then combinations of modules to create overall scales. The item-trait interaction assessed the questionnaire fit to a unidimensional model. A significant $\chi^{2}$ test for the overall item-trait interaction or individual items indicated misfit to the model and items were therefore removed. Item fit residuals, a summation of the difference between the observed score and that expected by the model for all persons, $\leq-2.5$ or $\geq 2.5$, indicated the items did not measure the same attribute as the domain and were also removed. ${ }^{13}$ Summary item and person fit residuals were itemperson interaction statistics transformed to approximate a $\mathrm{z}$ score; a mean (SD) residual of approximately 0 (1) indicated good fit to the model. The Person Separation Index (PSI) was determined to assess the ability of the KSQ to discriminate patients with different levels of health status impairment and test the reliability of the fit statistics. Internal consistency was assessed using Cronbach's $\alpha$ coefficient. The Likert response scale category thresholds for individual items were collapsed where thresholds were disordered to ensure they represented progressive increments in health status. ${ }^{14}$ The KSQ module and overall (total) scores were transformed to a range of $0-100$ ((actual score-lowest possible score/range $) \times 100) ; 100=$ best health status. The influence of age, gender, ethnicity, immunosuppressant medication and organ involvement on the patient's response to items was assessed for differential item functioning (DIF).

\section{Concurrent validity}

Concurrent validity, the assessment of an instrument against other standards that provide an indication of disease severity, was assessed by investigating the relationship between KSQ, organ-specific outcome measures and other health status questionnaires. All patients completed the 10-item Fatigue Assessment Scale (FAS) and Short Form-36 (SF36) questionnaire (general health status). ${ }^{15}{ }^{16}$ For patients with pulmonary sarcoidosis, forced vital capacity was assessed according to American Thoracic Society standards and patients completed the St George's Respiratory Questionnaire (SGRQ; respiratory health status) and the Medical Research Council (MRC) dyspnoea scale. ${ }^{17} 18$ For patients with cutaneous sarcoidosis, an independent dermatologist or trained physician completed a physician's global assessment score of the severity of skin disease $(0=$ no skin involvement, $4=$ very severe skin involvement) and patients completed the Dermatology life quality index (DLQI), a 10-item dermatology-specific health-related quality of life (HRQOL) tool. ${ }^{19}{ }^{20}$ For patients with ophthalmic sarcoidosis, visual acuity was assessed with a Snellen chart and a 25-item National Eye Institute Visual function HRQOL questionnaire (NEI-VFQ25) was administered. ${ }^{21}$ The sequence of administration of questionnaires was KSQ, SF36, SGRQ, MRC dyspnoea scale, FAS, DLQI and NEI-VFQ25. The questionnaires were administered prior to patients being assessed by the clinician or undergoing other procedures.

\section{Phase 3: repeatability testing}

A subgroup of consecutive patients with sarcoidosis completed the KSQ questionnaire on two occasions, 2 weeks apart to investigate repeatability. Only patients who reported no change in symptoms and considered stable by the clinician were recruited. Patients were excluded if they had a change in medication within the previous month.

\section{Analysis}

SPSS software, V.18 and RUMM 2030 were used for statistical analysis. Kolmogorov Smirnov test was used to check if the data were normally distributed. Mean and SD were used to describe parametric data. $\mathrm{p}<0.05$ was considered significant except when analysing multiple comparisons (concurrent validity); $\mathrm{p} \leq 0.001$, stronger evidence of association; $p \leq 0.01$ and $>0.001$, some evidence of association; and $\mathrm{p}<0.05$ and $>0.01$, possibly due to chance or only suggestive of association. Internal consistency was assessed using Cronbach's $\alpha$ coefficient (acceptable if $>0.7) .^{22}$ Correlations between parameters were assessed with Pearson's ( $r$ ) coefficient. Univariate analysis was performed to identify an association between health status (General health status and Lung modules) and the independent variables age, gender, ethnicity, smoking, forced expiratory volume in $1 \mathrm{~s}$ 
$\mathrm{FEV}_{1} \%$, forced vital capacity (FVC\%), transfer factor of the lung for carbon monoxide (TLCO\%), Scadding chest $\mathrm{x}$-ray (CXR) stage, number of organs involved and medications. Multivariable ordinary linear regression was used with forward selection to determine independent predictors of General health status and Lung; significant variables identified from univariate analysis $(p<0.05)$ were entered as independent variables. The repeatability of the KSQ was assessed with intraclass correlation coefficients and a Bland Altman plot. The 95\% limit of agreement was calculated as $1.96 \times \mathrm{SD}$ of within-subject differences. All patients gave written informed consent and the study was approved by the local research ethics committee (LondonSurrey Borders).

\section{RESULTS}

\section{Item generation}

Twenty-three patients with sarcoidosis (organ involvement: 22 lung, 10 skin, 7 eye) were interviewed to identify health themes and items. The interviews were discontinued when they did not yield new items. The preliminary KSQ items covered a range of health topics that included breathlessness, other respiratory symptoms, activities, fatigue, pain, social impact, psychological health, medications, health care, relationships and living with skin and eye disease (see online supplementary table 5). The preliminary KSQ was evaluated in 10 patients with sarcoidosis to assess item wording and suitability; no further changes were made. Five preliminary modules were developed during phase 1: General health status (GHS) (29 items), Lung (15 items), Medication (5 items), Skin (8 items) and Eye (8 items). They were administered to 207 patients with sarcoidosis to validate the questionnaire (table 1).

\section{Item reduction and Rasch analysis}

Twenty items were removed because of a significant floor effect or high inter-item correlation (figure 1). Rasch analysis removed poorly fitting items in the General health status (12 items), Lung (2), Skin (1) and Medication (1) modules. One Skin health item ('my skin has been itchy') was removed because of DIF between Caucasian and Afro-Caribbean patients and borderline redundancy (floor effect 39\%). There was no individual item misfit in remaining items and the item-trait interaction was nonsignificant, indicating good fit to the Rasch model (table 2 and online supplementary table 6). Further details regarding the removal of items are given in online supplementary table 5 .

The following overall health status scales (combined modules) remained unidimensional following Rasch analysis without eliminating further items: Lung health status $(\mathrm{L}+\mathrm{GHS})$, Skin health status (S+GHS), Eye health status $(\mathrm{E}+\mathrm{GHS})$ and Lung-Skin health status $(\mathrm{L}+\mathrm{S}+\mathrm{GHS})$. The addition of the medication module to overall Lung health status and Skin health status scales did not affect the fit to the Rasch model. The addition of the medications module to the overall Eye health status scale did not fit the Rasch model and the medication module was therefore scored separately in patients with eye disease. The PSIs for KSQ modules were 0.8-0.9 (table 2) and for overall health status scales $0.91-0.93$, suggesting they had good discriminant power to detect differing levels of health impairment. The person-item maps indicated the KSQ modules and overall scales detected health status across a wide spectrum of health status severity (figure 2 and online supplementary figures 4-11). There was no influence of age, gender, ethnicity, immunosuppressant medication or organ involvement on the response to items (DIF). The response scale thresholds were re-ordered for the following items: 1, 3, 5-11, 16-29. The KSQ scores
Table 1 Patient demographics

\begin{tabular}{|c|c|c|c|c|}
\hline & \multirow{2}{*}{$\begin{array}{l}\text { All } \\
\text { patients }\end{array}$} & \multicolumn{3}{|c|}{ Organ involvement } \\
\hline & & Lung & Skin & Eye \\
\hline Number & 207 & 184 & 54 & 45 \\
\hline Age, years, mean (SD) & $48(11)$ & $48(11)$ & 47 (9) & $49(13)$ \\
\hline Women, n (\%) & $112(54)$ & $98(53)$ & $31(57)$ & $28(62)$ \\
\hline \multicolumn{5}{|l|}{ Ethnicity, n (\%) } \\
\hline Caucasian & $120(58)$ & $105(57)$ & $17(31)$ & $19(42)$ \\
\hline Afro-Caribbean & $62(30)$ & $57(31)$ & $30(57)$ & $20(44)$ \\
\hline South Asian* & $21(10)$ & $18(10)$ & $5(9)$ & $5(11)$ \\
\hline Other & $4(2)$ & $4(2)$ & $2(4)$ & $1(3)$ \\
\hline \multicolumn{5}{|l|}{ Smoking status, n (\%) } \\
\hline Current & $25(12)$ & $24(13)$ & $3(6)$ & $3(7)$ \\
\hline Ex & $56(27)$ & $51(28)$ & $13(24)$ & $16(35)$ \\
\hline Never & $126(61)$ & $109(59)$ & $38(70)$ & $26(58)$ \\
\hline $\begin{array}{l}\text { Time since diagnosis, years, } \\
\text { mean (SD) }\end{array}$ & $7.7(6.6)$ & $7.5(6.2)$ & $6.9(4.9)$ & $6.9(5.9)$ \\
\hline \multicolumn{5}{|l|}{ Organs involved, n (\%) } \\
\hline Lungs & $184(89)$ & & & \\
\hline Skin & $54(26)$ & & & \\
\hline Eyes & $45(22)$ & & & \\
\hline Nervous system & $9(4)$ & & & \\
\hline Ear, nose and throat & 7 (3) & & & \\
\hline Liver & $8(4)$ & & & \\
\hline Lymph nodes & $6(3)$ & & & \\
\hline Bone and joints & $17(8)$ & & & \\
\hline Other & $14(7)$ & & & \\
\hline Number of organs involved & $1.8(0.9)$ & $1.8(0.9)$ & $2.6(0.9)$ & $2.7(0.8)$ \\
\hline $\begin{array}{l}\text { Physician Global Assessment } \\
\text { (Skin) }\end{array}$ & & & $1.4(0.93)$ & \\
\hline \multicolumn{5}{|l|}{ Visual acuity (best eye), n (\%) } \\
\hline Normal & & & & $25(56)$ \\
\hline Moderate impairment & & & & $14(31)$ \\
\hline Severe impairment & & & & $6(13)$ \\
\hline $\mathrm{FEV}_{1} \%$ predicted, mean (SD) & & $76(24)$ & & \\
\hline FVC\% predicted, mean (SD) & & $93(18)$ & & \\
\hline TLCO\% predicted, mean (SD) & & $63(16)$ & & \\
\hline \multicolumn{5}{|l|}{ Immunosuppressant, n (\%) } \\
\hline None & $60(29)$ & & & \\
\hline Prednisolone & $139(67)$ & & & \\
\hline Methotrexate & $29(14)$ & & & \\
\hline Azathioprine & $29(14)$ & & & \\
\hline Hydroxychloroquine & $27(13)$ & & & \\
\hline Other immunosuppression & 2 (1) & & & \\
\hline
\end{tabular}

*South Asian patients originating from India, Pakistan or Bangladesh. Visual acuity: normal: <20/30; moderate impairment: $>20 / 30$ but $<20 / 63$; severe impairment: $>20 / 63$.

Immunosuppressant medications were those prescribed at the time of the study. $\mathrm{FEV}_{1}$, forced expiratory volume in $1 \mathrm{~s}$; FVC, forced vital capacity; TLCO, diffusing capacity of the lung for carbon monoxide as \% predicted.

presented in this study were determined using the re-ordered thresholds.

\section{Administration of the KSQ}

The final KSQ consists of five modules: General health status (10 items), Lung (6 items), Medication (3 items), Skin (3 items) and Eye (7 items); see appendix. The General health status module is intended to be administered to all patients with sarcoidosis. In addition to this, patients also complete organspecific modules if relevant to their condition. Overall (total) health status score, the primary outcome measure, is determined 


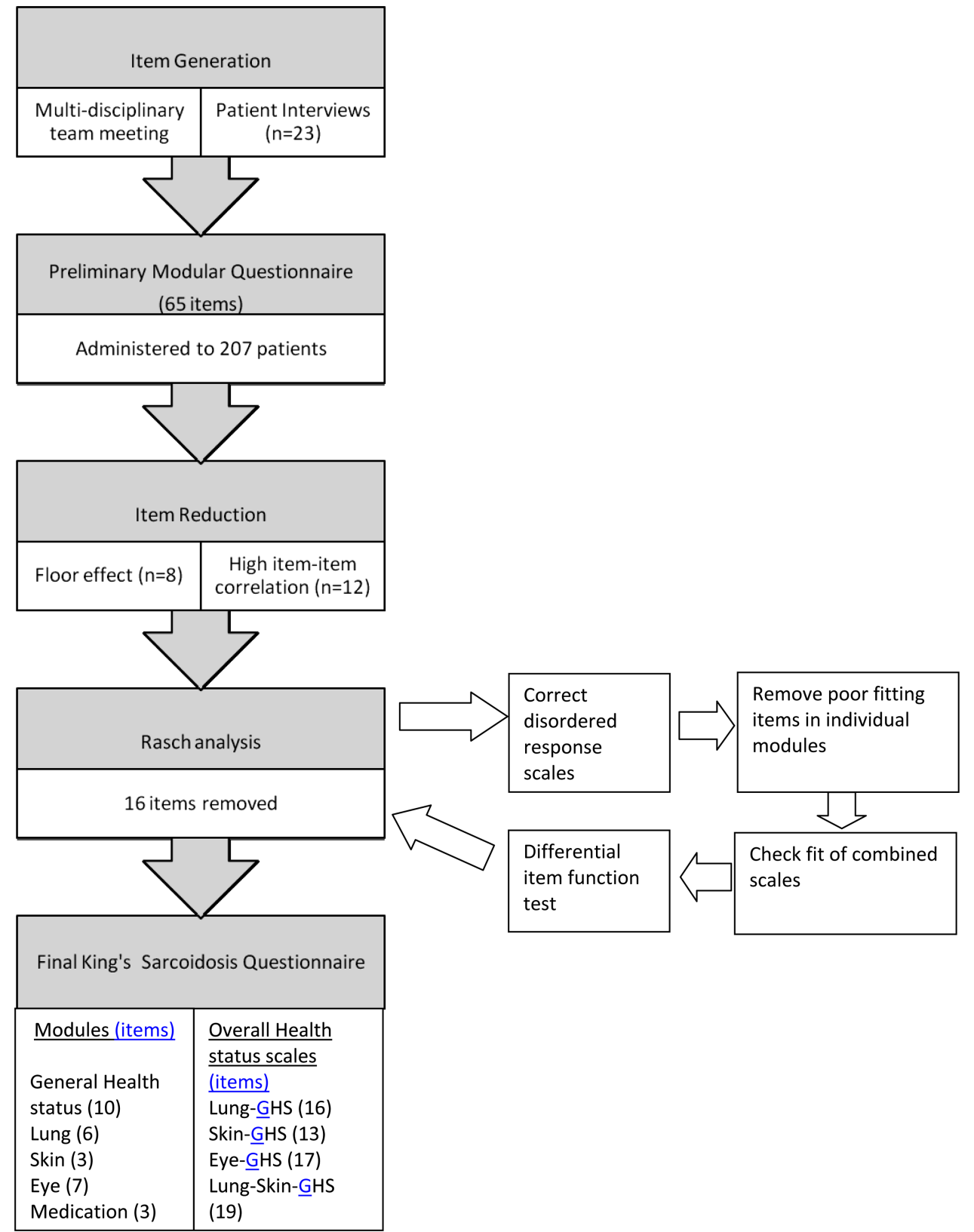

Figure 1 Summary of the development of the King's Sarcoidosis Questionnaire.

by combining modules as described in table 3 . The individual module scores are intended to identify the health domains affected. The medication module can be used in isolation or combined with overall lung and skin health status questionnaires but not eye health status. The patients complete the original seven-point Likert scale and scoring is calculated using a re-ordered scale for appropriate items.

\section{Validation}

The relationship between KSQ modules and their respective disease outcome measures was moderate to strong (table 4). Health status was significantly worse in patients with two or more organ disease compared with single-organ disease: mean (SEM) General health status score 44(3) versus 58(3); mean difference $13 ; 95 \%$ CI of difference 6-21; $p=0.001$. Patients with Scadding CXR stage 3-4 (severe) pulmonary disease compared with stage 1-2 disease had significantly worse Lung module scores: mean (SEM) 51(4) versus 63(3); mean difference 13;
95\% CI of difference $2-23 ; p=0.019$. Female patients had significantly worse General health status scores compared with male patients: mean (SEM) 45(3) versus 57(3); mean difference $12 ; 95 \% \mathrm{CI}$ of difference -20 to $-4 ; \mathrm{p}=0.002$. Univariate analysis identified an association between General health status and $\mathrm{FEV}_{1} \%, \mathrm{FVC} \%$, TLCO $\%$, gender, number of organs involved and immunosuppressant medications. Multivariable analysis (all patients) identified $\mathrm{FVC} \%$, gender, number of organs involved and immunosuppressant medications as independent predictors of General health status, accounting for $25 \%$ of the variance (see online supplementary table 7). TLCO $\%$ was not an independent predictor despite a weak association with General health status $(r=0.25, p=0.001)$. Patients taking immunosuppressive medication had worse FVC\% $(p=0.015)$, TLCO $\%$ $(\mathrm{p}<0.001)$ and greater organ involvement $(\mathrm{p}=0.048)$. Univariate analysis (lung patients only) identified an association between the Lung module and $\mathrm{FEV}_{1} \%, \mathrm{FVC} \%$, TLCO\%, Scadding CXR stage and immunosuppressant medications. Only 
Table 2 Summary of Rasch analysis of KSQ modules

\begin{tabular}{|c|c|c|c|c|c|}
\hline \multirow[b]{2}{*}{ Rasch statistics } & \multicolumn{5}{|l|}{ KSQ modules } \\
\hline & General health status & Lung & Skin & Eye & Medication \\
\hline Number of items & 10 & 6 & 3 & 7 & 3 \\
\hline$\chi^{2}$ fit statistic, $p$ value & 0.310 & 0.157 & 0.975 & 0.578 & 0.224 \\
\hline Mean item fit residual (SD) & $-0.01(1.5)$ & $-0.11(1.3)$ & $0.33(0.8)$ & $0.14(0.7)$ & $0.19(1.9)$ \\
\hline Mean person fit residual (SD) & $-0.3(1.1)$ & $-0.3(0.9)$ & $-0.3(1.2)$ & $-0.2(1.0)$ & $-0.2(0.7)$ \\
\hline Person separation index & 0.90 & 0.78 & 0.79 & 0.83 & 0.70 \\
\hline Cronbach's $\alpha$ coefficient & 0.93 & 0.86 & 0.84 & 0.88 & 0.70 \\
\hline
\end{tabular}

FVC\% was an independent predictor of the Lung module, accounting for $15 \%$ of the variance. There was no multicollinearity. Multivariable analysis was not performed for Skin, Eye and Medication modules due to insufficient sample size. Repeatability was investigated in 39 patients (36 lung, 16 skin, 15 eye involvement). Intraclass correlation coefficients suggested good repeatability; KSQ General health status 0.96, Lung 0.90, Skin 0.92, Eye 0.96 and Medications 0.90. A Bland-Altman plot of KSQ Lung module score repeatability is shown in figure 3. Bland-Altman plots for the other KSQ modules were also consistent, with the KSQ being a highly repeatable measure. Ninety-seven percent of patients had no difficulty in completing the KSQ. The mean (SD) time patients took to complete the KSQ was $10(8) \mathrm{min}$.

\section{DISCUSSION}

The KSQ is a health status questionnaire developed and validated for patients with sarcoidosis. It is brief, adaptable to individual patients and the first tool to assess organ-specific health status. The KSQ is simple to administer and most patients found it easy to complete.

The KSQ items were generated following detailed patient interviews exploring the impact of sarcoidosis on their health. The preliminary KSQ was validated by a systematic statistical approach with Rasch analysis, commonly used in the development of health status tools. Redundant items were removed when possible whilst retaining essential questionnaire measurement characteristics. Rasch analysis confirmed the KSQ modules and overall scales had good interval scaling of items and were unidimensional. The person-item threshold distribution of the KSQ was large, confirming it assessed health status across a wide spectrum. The correlation with lung function in patients with pulmonary sarcoidosis was moderate, analogous to that seen in chronic obstructive pulmonary disease, consistent with the view that health status questionnaires assess a unique aspect of disease severity not captured by objective measures. ${ }^{23} 24$ The concurrent validity of the KSQ compared with the SGRQ was good, suggesting the removal of redundant items did not compromise the KSQ's ability to measure health status. The KSQ correlated more strongly with the SGRQ than the SF36. The weak association with the SF36 raised the possibility that the SF36 did not fully identify the health issues specific for sarcoidosis since it was a generic instrument. The KSQ Skin and Eye modules also related well to organ-specific measures of disease severity. The KSQ detected differences in health status in patients with single-organ compared with multi-organ disease; further studies should investigate whether the KSQ can discriminate health status severity in individual patients.

We chose to develop a flexible, modular instrument that assessed the most frequently involved organs in sarcoidosis to reflect the varied and changing phenotype often seen in clinical practice. The organ-specific modules could be combined with the General health status module to assess overall health status. The General health status module was administered to all patients and could potentially be used to compare the health status of patients with different organ involvement. It may be possible to assess rarer forms of sarcoidosis such as neurological and cardiac disease with the General health status module since it comprises generic items relevant to most patients but this needs to be validated. Further studies are needed to develop disease-specific modules for rarer forms of sarcoidosis. The primary outcome score for the KSQ varies according to organ involvement. For example, in patients with pulmonary sarcoidosis the General health status module is combined with the Lung module to give a total score. There was a very strong correlation between KSQ General health status and fatigue assessed with the FAS $\left(r^{2}=0.74\right)$. Fatigue is a very common and troublesome symptom. The data from this study confirm the findings of previous studies reporting a major impact of fatigue on the wellbeing of patients. ${ }^{4}$ There was no DIF for ethnicity,
Figure 2 Person-item threshold distribution for Lung-Health Status score. The $x$-axis represents severity of health status in logits (log transformed units). The item threshold frequency represents the number of item responses that measure health status at each level of impairment. This figure demonstrates a good spread of item thresholds across the spectrum of health status.

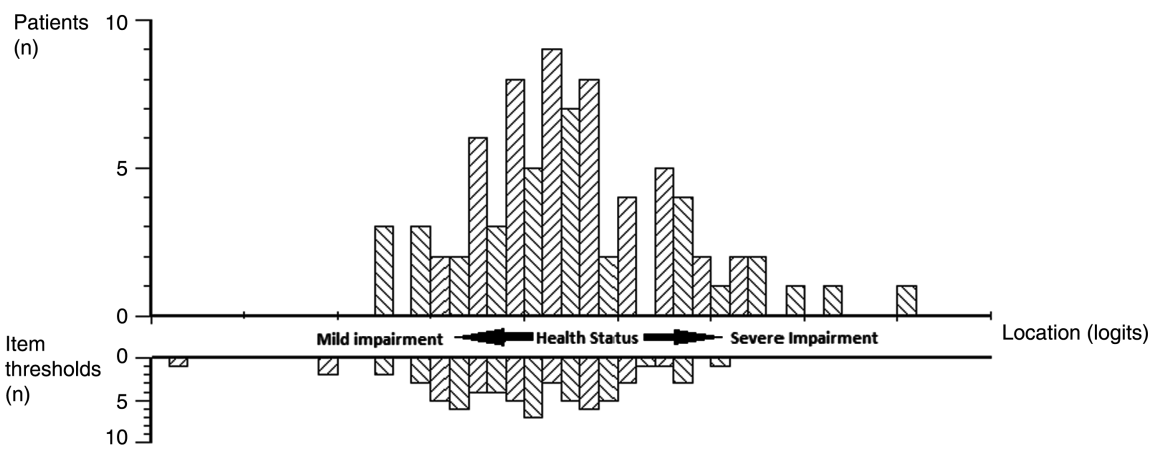


Table 3 KSQ: final format

\begin{tabular}{lc}
\hline KSQ & Items \\
\hline Modules & 10 \\
$\quad$ General health Status (GHS) & 6 \\
Lung (L) & 3 \\
Skin (S) & 7 \\
Eye (E) & 3 \\
Medication (M) & 16 \\
Overall HRQOL Scales & 13 \\
Lung-HS (L+GHS) & 17 \\
Skin-HS (S+GHS) & 19 \\
Eye-HS (E+GHS) & \\
Lung-Skin-HS (L+S+GHS) & \\
\hline $\begin{array}{l}\text { All scores range from 0 to 100, 100=best health status. Health status is assessed by } \\
\text { combining the General health status module with organ-specific modules and the } \\
\text { medication module if appropriate. } \\
\text { HRQOL, health-related quality of life; KSQ, King's Sarcoidosis Questionnaire. }\end{array}$
\end{tabular}

suggesting that the KSQ was valid for different races. Our findings are consistent with those of Cox et $a l^{9}$ who also found no effect of ethnicity on health status. The relationship between ethnicity, health status and disease severity is likely to be complex and multifactorial and needs further investigation. The KSQ was developed in a large population comprising Caucasian, Afro-Caribbean and other ethnic groups, increasing our confidence that it could be used in a wide range of patients. Female patients had worse health status than male patients, consistent with previous studies. ${ }^{3} 25$

There is one other questionnaire that can be used to assess health status specifically in sarcoidosis, the Sarcoidosis Health Status Questionnaire (SHQ) developed in 2001. ${ }^{9}$ This is a 29-item questionnaire administered in its entirety. A limitation of the SHQ is that it cannot be tailored to individual clinical phenotypes. This could potentially impact the sensitivity and the responsiveness of the questionnaire. A further limitation is that it contains few items that assess fatigue (one item), medications (one item) and extra-pulmonary organ involvement (skin (one item) and eye disease (one item)). Furthermore, the SHQ has not been validated for use in skin and eye disease. In contrast, organ-specific modules were developed and validated for the KSQ and it can therefore be adapted for individual patients. The KSQ is considerably briefer for most patients, for example, the assessment of lung health status comprises 16 items. This is likely to be important in research studies when patients are often subjected to multiple time-consuming assessments. The KSQ was developed using Rasch analysis in contrast to clinical impact methodology used for the SHQ and therefore has the advantage that it is a validated unidimensional scale with optimal scaling properties. ${ }^{14}$ The concurrent validity of the KSQ for pulmonary disease was better than that of the SHQ: stronger relationship with SGRQ ( $\mathrm{r}=-0.66$ to -0.83 vs -0.62 to -0.73 ), FVC ( $r=0.49$ vs 0.19$)$ and MRC dyspnoea score $(r=$ -0.62 vs -0.22$).^{9}$ Furthermore, the KSQ is highly repeatable (test/retest); this has not been reported for the SHQ. The SGRQ, a generic respiratory health status questionnaire could also be used to assess health status in sarcoidosis but has the disadvantage that it is considerably longer (50 items), does not assess skin and eye disease and is likely to be less responsive than disease-specific questionnaires.

There are limitations with health status questionnaire development methodology. It is possible that some items eliminated during the development process such as sleep disturbance and sexual health may have contributed significantly to health status in some patients. Our aim was to develop a questionnaire that could quantify health status with the least number of items, whilst retaining validity, so that it remains practical for clinical use. Health status questionnaires are not a substitute for identifying health-related issues obtained from a detailed history. We eliminated items that were infrequent, redundant, contributed weakly to health status assessment or did not conform to optimal scaling properties. It is possible that health issues relevant to sarcoidosis that were not included in the final version of the KSQ were assessed indirectly by their impact on related health items. For example, sleep disturbance is likely to be associated with difficulty maintaining concentration and fatigue. ${ }^{11}$ Sleep disturbance is troublesome in a subgroup of patients with sarcoidosis and it is perhaps more appropriate to assess it with sleep-specific tools such as the Epworth Sleepiness Scale. ${ }^{26}$ Immunosuppressant medication

Table 4 The relationship between KSQ and disease-specific outcome measures

\begin{tabular}{|c|c|c|c|c|c|c|c|c|c|c|c|c|c|}
\hline & \multirow{2}{*}{\multicolumn{2}{|c|}{$\frac{\text { Generic QOL }}{\text { SF36 }}$}} & \multirow{3}{*}{$\begin{array}{l}\text { Fatigue } \\
\text { FAS } \\
\text { Total }\end{array}$} & \multicolumn{6}{|l|}{ Lung } & \multicolumn{2}{|l|}{ Skin } & \multicolumn{2}{|l|}{ Eye } \\
\hline & & & & \multirow{2}{*}{$\begin{array}{l}\text { FVC } \\
\% \text { Pred }\end{array}$} & \multicolumn{4}{|l|}{ SGRQ } & \multirow{2}{*}{$\begin{array}{l}\text { MRC } \\
\text { Breathlessness }\end{array}$} & \multirow{2}{*}{$\begin{array}{l}\text { DLQI } \\
\text { Total }\end{array}$} & \multirow[t]{2}{*}{ PGA } & \multirow{2}{*}{$\begin{array}{l}\text { VFQ-25 } \\
\text { Total }\end{array}$} & \multirow[t]{2}{*}{ VA } \\
\hline & PCS & MCS & & & Sym & Act & $\operatorname{Imp}$ & Tot & & & & & \\
\hline \multicolumn{14}{|l|}{ KSQ modules } \\
\hline General health status & 0.64 & 0.70 & -0.86 & - & -0.49 & -0.67 & -0.66 & -0.70 & -0.57 & -0.35 & - & 0.66 & - \\
\hline Lung & 0.71 & 0.39 & -0.60 & 0.47 & -0.74 & -0.78 & -0.78 & -0.85 & -0.58 & - & - & - & - \\
\hline Skin & $0.32^{*}$ & 0.47 * * & $-0.42 * *$ & - & - & - & - & - & - & -0.67 & -0.53 & - & - \\
\hline Eye & $0.56^{* *}$ & $0.55^{* *}$ & -0.59 & - & - & - & - & - & - & - & - & 0.80 & $-0.56^{* *}$ \\
\hline Medication & $0.25^{*}$ & $0.29 * *$ & -0.35 & - & $-0.31^{* *}$ & -0.33 & -0.41 & -0.40 & -0.29 & -0.38 & - & $0.27^{*}$ & - \\
\hline \multicolumn{14}{|l|}{ Overall Health Status } \\
\hline Lung+GHS & 0.73 & 0.62 & -0.82 & 0.49 & -0.66 & -0.78 & -0.77 & -0.83 & -0.62 & - & - & - & - \\
\hline Skin+GHS & 0.58 & 0.69 & -0.78 & - & - & - & - & - & - & $-0.48^{* *}$ & $-0.38^{*}$ & - & - \\
\hline Eye+GHS & 0.60 & 0.66 & -0.82 & - & - & - & - & - & - & - & - & 0.80 & $-0.45^{* *}$ \\
\hline Lung+Skin+GHS & 0.70 & 0.63 & -0.79 & 0.45 & -0.65 & -0.79 & -0.76 & -0.83 & -0.64 & $-0.47^{* *}$ & $-0.38^{*}$ & - & - \\
\hline
\end{tabular}

Data shown are Pearson's correlation coefficients for organ-specific comparisons. All $p<0.001$ (stronger evidence of association) except ** $p<0.01$ and $\geq 0.001$ (some evidence of association) and ${ }^{*} p<0.05$ and $>0.01$ (possibly due to chance or only suggestive of association).

Act, activity; DLQI, Dermatology Life Quality Index; FAS, Fatigue Assessment Scale; FVC, forced vital capacity; HS, health status; Imp, impact; KSQ, King's Sarcoidosis Questionnaire; MRC, Medical Research Council dyspnoea scale; PGA, Physicians Global Assessment; SGRQ, St George's Respiratory Questionnaire-Symptoms; Sym, symptoms; Tot, total; SF-36 PCS, Short Form 36 Physical Component Summary; SF-36 MCS, Short Form 36 Mental Component Summary; VA, visual acuity; VFQ-25, Visual Function Questionnaire (25 items); -, not applicable. 


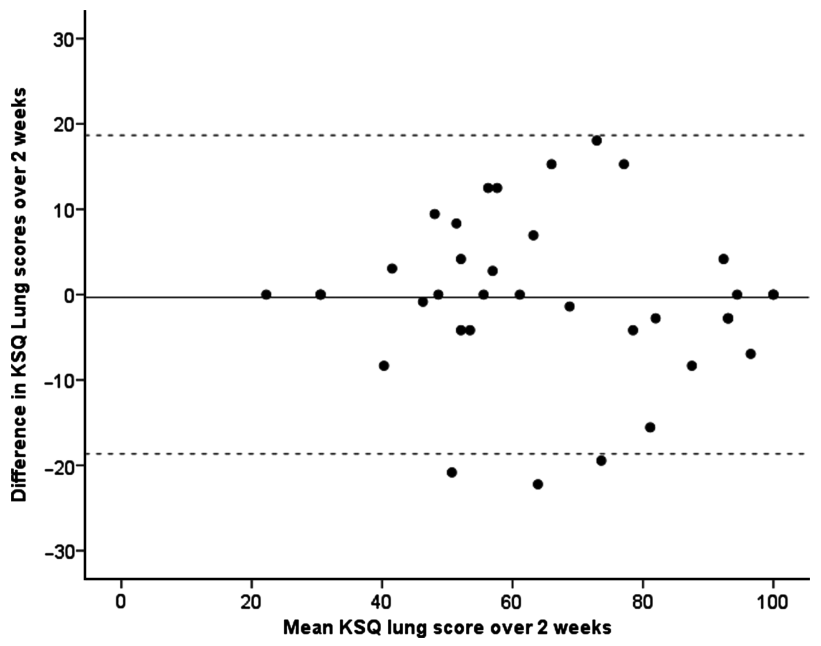

Figure 3 Bland Altman plot of repeatability of King's Sarcoidosis Questionnaire Lung module. Solid line represents mean difference and dashed lines represent $95 \%$ limits of agreement.

was an independent predictor of General health status. The use of immunosuppressant medications was associated with more severe disease since these patients had worse lung function and a greater number of organs involved, consistent with the findings of a previous study. ${ }^{9}$ Furthermore, there was no DIF for patients taking immunosuppressive medications. There was no interaction between medications and the Lung module. Another possibility is that side effects of medications, particularly corticosteroids, may have impacted health status more than the effect of sarcoidosis in some patients. Longitudinal studies are needed in patients matched for disease severity to investigate the temporal relationship between medications and health status. The impact of medications should be assessed specifically with the KSQ medication module. The person-item threshold distribution suggested that the KSQ items were marginally more focused towards patients with milder health status. The high PSI for the KSQ was consistent with its ability to discriminate differing levels of health status. However, the responsiveness was not investigated and needs to be assessed in large longitudinal studies and in patients with acute exacerbation of sarcoidosis.

The KSQ has a number of potential applications. The KSQ is a quick and valid tool to identify health status issues important to patients in the clinic. Furthermore, it could be used to help formulate shared care plans between the patient and physician. Our study suggests the KSQ is a valid single point measure that could be used in cross-sectional studies. In summary, the KSQ is brief, easy to administer and well validated. It represents an advance in the assessment of sarcoidosis.

Acknowledgements We would like to thank the staff in the clinics and lung function units at King's College Hospital and Royal Brompton Hospital for their assistance in characterisation of patients. We would like to thank Dr Barry Gray and Dr Greg Keir for their assistance in recruiting patients. We would also like to thank Dr Sabrina Bajwah, Dr Rachel Morris-Jones, Professor Roderick Hay and Dr Saquib Bashir for their input into methodology, Professor Andrew Finlay for permission for use of the DLQI and Professors Mike Morgan and Sally Singh for reviewing the KSQ questionnaire.

Reprints of KSQ: the King's Sarcoidosis Questionnaire (02011 is protected by copyright; King's College Hospital NHS Foundation Trust. Reprints of the KSQ are available from the corresponding author.

Contributors Conception and obtained funding: $\mathrm{SB}$ and $\mathrm{IH}$; study design: all; recruitment: $A P, D C, G L, T M, E R, A W$ and $S B$; analysis and interpretation: $A P, R S$, $A W, I H$ and $S B$; data collection: $A P$; wrote the manuscript: $A P$ and $S B$; revised the manuscript: $I H, R S, A W, D C, G L, T M$ and $E R$.

Funding King's College Hospital Charity. AW, TM and ER are supported by the NIHR Respiratory Disease Biomedical Research Unit at the Royal Brompton and Harefield NHS Foundation Trust and Imperial College London.
Competing interests None.

Provenance and peer review Not commissioned; externally peer reviewed.

Data sharing statement All data published in full.

\section{REFERENCES}

1 Statement on sarcoidosis. Joint statement of the American Thoracic Society (ATS), the European Respiratory Society (ERS) and the World Association of Sarcoidosis and Other Granulomatous Disorders (WASOG) adopted by the ATS Board of Directors and by the ERS Executive Committee, February 1999. Am J Respir Crit Care Med 1999;160:736-55.

2 Baughman RP, Teirstein AS, Judson MA, et al. Clinical characteristics of patients in a case control study of sarcoidosis. Am J Respir Crit Care Med 2001;164:1885-9.

3 Michielsen HJ, Peros-Golubicic T, Drent M, et al. Relationship between symptoms and quality of life in a sarcoidosis population. Respiration 2007;74:401-5.

4 Michielsen HJ, Drent M, Peros-Golubicic T, et al. Fatigue is associated with quality of life in sarcoidosis patients. Chest 2006;130:989-94.

5 Chang B, Steimel J, Moller DR, et al. Depression in sarcoidosis. Am J Respir Crit Care Med 2001;163:329-34.

6 Wasfi YS, Rose CS, Murphy JR, et al. A new tool to assess sarcoidosis severity. Chest 2006:129:1234-45.

7 De Vries J, Drent M. Quality of life and health status in interstitial lung diseases. Curr Opin Pulm Med 2006:12:354-8.

8 Drent $\mathrm{M}$, Wirnsberger RM, Breteler $\mathrm{MH}$, et al. Quality of life and depressive symptoms in patients suffering from sarcoidosis. Sarcoidosis Vasc Diffuse Lung Dis 1998; 15:59-66.

9 Cox CE, Donohue JF, Brown CD, et al. The Sarcoidosis Health Questionnaire: a new measure of health-related quality of life. Am J Respir Crit Care Med 2003;168:323-9.

10 Judson MA, Baughman RP, Teirstein AS, et al. Defining organ involvement in sarcoidosis: the ACCESS proposed instrument. ACCESS Research Group. A Case Control Etiologic Study of Sarcoidosis. Sarcoidosis Vasc Diffuse Lung Dis 1999;16:75-86

11 Birring SS, Prudon B, Carr AJ, et al. Development of a symptom specific health status measure for patients with chronic cough: Leicester Cough Questionnaire (LCQ). Thorax 2003:58:339-43.

12 Rasch G. Probabilistic Models for Some Intelligence and Attainment Tests. Chicago, Illinois: University of Chicago Press, 1960.

13 Yorke J, Jones PW, Swigris JJ. Development and validity testing of an IPF-specific version of the St George's Respiratory Questionnaire. Thorax 2010;65:921-6.

14 Tennant A, Conaghan PG. The Rasch measurement model in rheumatology: what is it and why use it? When should it be applied, and what should one look for in a Rasch paper? Arthritis Rheum 2007:57:1358-62.

15 Michielsen HJ, De VJ, Van Heck GL. Psychometric qualities of a brief self-rated fatigue measure: the fatigue assessment scale. J Psychosom Res 2003;54:345-52.

16 Brazier JE, Harper R, Jones NM, et al. Validating the SF-36 health survey questionnaire: new outcome measure for primary care. BMJ 1992;305:160-4.

17 Standardization of Spirometry, 1994 Update. American Thoracic Society. Am J Respir Crit Care Med 1995;152:1107-36.

18 Jones PW, Quirk FH, Baveystock CM, et al. A self-complete measure of health status for chronic airflow limitation. The St. George's Respiratory Questionnaire. Am Rev Respir Dis 1992:145:1321-7. 
19 Finlay AY, Khan GK. Dermatology Life Quality Index (DLQI)—a simple practical measure for routine clinical use. Clin Exp Dermatol 1994;19:210-16.

20 Langley RG, Ellis CN. Evaluating psoriasis with Psoriasis Area and Severity Index Psoriasis Global Assessment, and Lattice System Physician's Global Assessment. Am Acad Dermatol 2004:51:563-9.

21 Mangione CM, Lee PP, Gutierrez PR, et al. Development of the 25-item Nationa Eye Institute Visual Function Questionnaire. Arch Ophthalmol 2001:119:1050-8.

22 Terwee CB, Bot SD, de Boer MR, et al. Quality criteria were proposed for measurement properties of health status questionnaires. J Clin Epidemiol 2007:60:34-42.

\section{APPENDIX}

\section{KING'S SARCOIDOSIS QUESTIONNAIRE @}

This questionnaire is designed to assess the impact of sarcoidosis on various aspects of your life. Read each question carefully and answer by CIRCLING the response that best applies to you. Please answer ALL questions, as honestly as you can. This questionnaire is confidential. All questions relate to how SARCOIDOSIS has affected your health.

Please note the KSQ is scored using a re-ordered response scale; this is available from the corresponding author. The patients however complete the scale below.

\section{General Health status}

\begin{tabular}{|c|c|c|c|c|c|c|c|c|}
\hline & In the last 2 weeks... & $\begin{array}{l}\text { All of the } \\
\text { time }\end{array}$ & $\begin{array}{l}\text { Most of the } \\
\text { time }\end{array}$ & $\begin{array}{l}\text { A good bit of } \\
\text { the time }\end{array}$ & $\begin{array}{l}\text { Some of } \\
\text { the time }\end{array}$ & $\begin{array}{l}\text { A little of } \\
\text { the time }\end{array}$ & $\begin{array}{l}\text { Hardly any of } \\
\text { the time }\end{array}$ & $\begin{array}{l}\text { None of } \\
\text { the time }\end{array}$ \\
\hline 1 & I have felt frustrated & 1 & 2 & 3 & 4 & 5 & 6 & 7 \\
\hline 2 & I have had trouble concentrating & 1 & 2 & 3 & 4 & 5 & 6 & 7 \\
\hline 3 & I have lacked motivation & 1 & 2 & 3 & 4 & 5 & 6 & 7 \\
\hline 4 & I have felt tired & 1 & 2 & 3 & 4 & 5 & 6 & 7 \\
\hline 5 & I have felt anxious & 1 & 2 & 3 & 4 & 5 & 6 & 7 \\
\hline 6 & I have felt aches and pains in my muscles/joints & 1 & 2 & 3 & 4 & 5 & 6 & 7 \\
\hline 7 & I have felt embarrassed & 1 & 2 & 3 & 4 & 5 & 6 & 7 \\
\hline 8 & I have worried about my weight & 1 & 2 & 3 & 4 & 5 & 6 & 7 \\
\hline \multirow[t]{2}{*}{9} & I have worried about my sarcoidosis & 1 & 2 & 3 & 4 & 5 & 6 & 7 \\
\hline & In the last 2 weeks... & $\begin{array}{l}\text { A huge } \\
\text { amount }\end{array}$ & $\begin{array}{l}\text { Considerable } \\
\text { amount }\end{array}$ & $\begin{array}{l}\text { A moderate } \\
\text { amount }\end{array}$ & $\begin{array}{l}\text { A Modest } \\
\text { amount }\end{array}$ & $\begin{array}{l}\text { A small } \\
\text { amount }\end{array}$ & A tiny amount & None at al \\
\hline 10 & $\begin{array}{l}\text { Tiredness has interfered with my normal social } \\
\text { activities such as going out with friends/family }\end{array}$ & 1 & 2 & 3 & 4 & 5 & 6 & 7 \\
\hline
\end{tabular}

\section{Lung}

In the last 2 weeks..

11 My cough has caused me pain/discomfort

12 I have been breathless climbing stairs or walking up slight inclines

13 I have had to take deep breaths, also known as 'air hunger'

14 My chest has felt tight

15 I have had episodes of breathlessness

16 I have experienced chest pains
24 Jones PW. Health status measurement in chronic obstructive pulmonary disease. Thorax 2001;56:880-7.

25 Bourbonnais JM, Samavati L. Effect of gender on health related quality of life in sarcoidosis. Sarcoidosis Vasc Diffuse Lung Dis 2010;27:96-102.

26 Johns MW. A new method for measuring daytime sleepiness: the Epworth sleepiness scale. Sleep 1991;14:540-5. 


\section{MEDICATION}

\begin{tabular}{|c|c|c|c|c|c|c|c|c|}
\hline & In the last 2 weeks... & $\begin{array}{l}\text { A huge } \\
\text { amount }\end{array}$ & $\begin{array}{l}\text { Considerable } \\
\text { amount }\end{array}$ & $\begin{array}{l}\text { A moderate } \\
\text { amount }\end{array}$ & $\begin{array}{l}\text { A Modest } \\
\text { amount }\end{array}$ & $\begin{array}{l}\text { A small } \\
\text { amount }\end{array}$ & $\begin{array}{l}\text { A tiny } \\
\text { amount }\end{array}$ & $\begin{array}{l}\text { None at } \\
\text { all }\end{array}$ \\
\hline 17 & $\begin{array}{l}\text { I have worried about side effects of my } \\
\text { medication for sarcoidosis }\end{array}$ & 1 & 2 & 3 & 4 & 5 & 6 & 7 \\
\hline 18 & $\begin{array}{l}\text { I have felt worse because of my medication for } \\
\text { sarcoidosis }\end{array}$ & 1 & 2 & 3 & 4 & 5 & 6 & 7 \\
\hline 19 & $\begin{array}{l}\text { I have gained weight because of my medication } \\
\text { for sarcoidosis }\end{array}$ & 1 & 2 & 3 & 4 & 5 & 6 & 7 \\
\hline
\end{tabular}

\section{SKIN}

\begin{tabular}{|c|c|c|c|c|c|c|c|c|}
\hline & In the last 2 weeks... & $\begin{array}{l}\text { A huge } \\
\text { amount }\end{array}$ & $\begin{array}{l}\text { Considerable } \\
\text { amount }\end{array}$ & $\begin{array}{l}\text { A moderate } \\
\text { amount }\end{array}$ & $\begin{array}{l}\text { A Modest } \\
\text { amount }\end{array}$ & $\begin{array}{l}\text { A small } \\
\text { amount }\end{array}$ & A tiny amount & None at all \\
\hline 20 & I have been bothered by my skin problems & 1 & 2 & 3 & 4 & 5 & 6 & 7 \\
\hline \multirow[t]{2}{*}{21} & I have been concerned about changes in & 1 & 2 & 3 & 4 & 5 & 6 & 7 \\
\hline & & $\begin{array}{l}\text { All of the } \\
\text { time }\end{array}$ & Most of the time & $\begin{array}{l}\text { A good bit of } \\
\text { the time }\end{array}$ & $\begin{array}{l}\text { Some of the } \\
\text { time }\end{array}$ & $\begin{array}{l}\text { A little of the } \\
\text { time }\end{array}$ & $\begin{array}{l}\text { Hardly any of } \\
\text { the time }\end{array}$ & $\begin{array}{l}\text { None of the } \\
\text { time }\end{array}$ \\
\hline 22 & I have been embarrassed about my skin & 1 & 2 & 3 & 4 & 5 & 6 & 7 \\
\hline
\end{tabular}

\section{EYES}

\begin{tabular}{|c|c|c|c|c|c|c|c|c|}
\hline & In the last 2 weeks... & $\begin{array}{l}\text { All of the } \\
\text { time }\end{array}$ & Most of the time & $\begin{array}{l}\text { A good bit of the } \\
\text { time }\end{array}$ & $\begin{array}{l}\text { Some of the } \\
\text { time }\end{array}$ & $\begin{array}{l}\text { A little of the } \\
\text { time }\end{array}$ & $\begin{array}{l}\text { Hardly any of the } \\
\text { time }\end{array}$ & $\begin{array}{l}\text { None of the } \\
\text { time }\end{array}$ \\
\hline 23 & I have had dry eyes & 1 & 2 & 3 & 4 & 5 & 6 & 7 \\
\hline 24 & $\begin{array}{l}\text { I have had difficulty with } \\
\text { bright lights }\end{array}$ & 1 & 2 & 3 & 4 & 5 & 6 & 7 \\
\hline 25 & My eyes have been red & 1 & 2 & 3 & 4 & 5 & 6 & 7 \\
\hline 26 & $\begin{array}{l}\text { I have had pain in/or around } \\
\text { the eyes }\end{array}$ & 1 & 2 & 3 & 4 & 5 & 6 & 7 \\
\hline \multirow[t]{2}{*}{27} & I have had difficulty reading & 1 & 2 & 3 & 4 & 5 & 6 & 7 \\
\hline & & $\begin{array}{l}\text { A huge } \\
\text { amount }\end{array}$ & $\begin{array}{l}\text { Considerable } \\
\text { amount }\end{array}$ & $\begin{array}{l}\text { A moderate } \\
\text { amount }\end{array}$ & $\begin{array}{l}\text { A Modest } \\
\text { amount }\end{array}$ & $\begin{array}{l}\text { A small } \\
\text { amount }\end{array}$ & A tiny amount & None at all \\
\hline 28 & I have had blurred vision & 1 & 2 & 3 & 4 & 5 & 6 & 7 \\
\hline 29 & $\begin{array}{l}\text { I have been worried about my } \\
\text { eyesight }\end{array}$ & 1 & 2 & 3 & 4 & 5 & 6 & 7 \\
\hline
\end{tabular}

